\title{
Methotrexate modulates the kinetics of adenosine in humans in vivo
}

\author{
N P Riksen, P Barrera, P H H van den Broek, P L C M van Riel, P Smits, G A Rongen

See end of article for authors' affiliations

.....................

Correspondence to: Dr N P Riksen, Department of PharmacologyToxicology 149, Radboud University Nijmegen Medical Centre, Geert Grooteplein 21, 6525 EZ Nijmegen, The

Netherlands; N.Riksen@ aig.umen.nl

Accepted

19 November 2005

Published Online First

24 January 2006
Background: Animal studies suggest that the anti-inflammatory effect of methotrexate (MTX) is mediated by increased adenosine concentrations.

Objective: To assess the effect of MTX on the vasodilator effects of adenosine and the nucleoside uptake inhibitor, dipyridamole, in humans in vivo as a marker for changes in adenosine kinetics.

Methods: Ten patients with active arthritis were treated with MTX (15 mg/week). Measurements were performed before and after 12 weeks of treatment. At these time points, the activity of adenosine deaminase was measured in isolated lymphocytes, and forearm blood flow (FBF) was determined by venous occlusion plethysmography during administration of adenosine and dipyridamole into the brachial artery.

Results: The $\mathrm{V}_{\max }$ of adenosine deaminase in lymphocytes was reduced by MTX treatment $(p<0.05)$. MTX significantly enhanced vasodilator response to adenosine $(0.5$ and $1.5 \mu \mathrm{g} / \mathrm{min} / \mathrm{dl}$ of forearm tissue; mean (SE) FBF ratio increased from $1.2(0.2)$ to $1.4(0.2)$ and $2.2(0.2) \mathrm{ml} / \mathrm{dl} / \mathrm{min}$, respectively, before and from $1.3(0.1)$ to $1.8(0.2)$ and $3.2(0.5) \mathrm{ml} / \mathrm{dl} / \mathrm{min}$ during MTX treatment; $\mathrm{p}<0.05)$. Also, dipyridamoleinduced vasodilatation ( 30 and $100 \mu \mathrm{g} / \mathrm{min} / \mathrm{dl}$ ) was enhanced by MTX (FBF ratio increased from 1.2 $(0.2)$ to $1.5(0.3)$ and $1.8(0.2)$, respectively, before and from $1.3(0.1)$ to $1.8(0.2)$ and $2.4(0.4)$ during MTX treatment; $p<0.05$ ).

Conclusions: MTX treatment inhibits deamination of adenosine and potentiates adenosine-induced vasodilatation. Also dipyridamole-induced vasodilatation is enhanced by MTX treatment, suggesting an increased extracellular formation of adenosine. These effects on the adenosine kinetics in humans may contribute to the therapeutic efficacy of MTX.
B ecause of its favourable efficacy and toxicity profile, methotrexate (MTX) is often the first disease modifying antirheumatic drug (DMARD) prescribed in patients with rheumatoid arthritis. ${ }^{1}$ The mechanism of action of MTX remains controversial, although it is generally accepted that it differs from the antiproliferative effect of high dose MTX in the treatment of neoplasms. ${ }^{2}{ }^{3}$ In the past decade, animal studies have provided several lines of evidence that the antiinflammatory effect of MTX is mediated by adenosine receptor stimulation. ${ }^{2}$

Adenosine is a purine-nucleoside that is formed both intraand extracellularly by degradation of adenosine monophosphate (AMP) (fig 1). ${ }^{4}$ Degradation of adenosine by the enzymes adenosine deaminase and adenosine kinase, however, is confined to the intracellular compartment. Thus, facilitated transport of adenosine over the cellular membrane is mainly directed from outside the cell inwards. ${ }^{5}$ There are four types of G-protein coupled adenosine receptor, which are designated $A_{1}, A_{2 A}, A_{2 B}$, and $A_{3}$ receptors. ${ }^{4}$ Stimulation of the $\mathrm{A}_{2 \mathrm{~A}}$ receptor potently inhibits inflammation, ${ }^{6}$ and induces

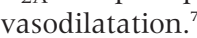

In humans, evidence for a role of adenosine is either indirect $^{89}$ or controversial. ${ }^{10-14}$ This is mainly due to methodological shortcomings and the highly complicated determination of the adenosine concentration. ${ }^{15}$

In this study we aimed at assessing whether adenosine receptor stimulation is indeed increased by MTX treatment in humans in vivo. We avoided the methodological problems of measuring adenosine concentrations by determining the vasodilator response to adenosine and dipyridamole, reflecting alterations in degradation and formation of adenosine, respectively. Dipyridamole is a potent inhibitor of the equilibrative nucleoside transporter (fig 1), ${ }^{16}$ and consequently increases extracellular adenosine, and induces vasodilatation, at a rate proportional to extracellular formation of adenosine. Finally, we also determined the activity of adenosine deaminase in lymphocytes and erythrocytes to explore the mechanism of the altered adenosine kinetics by MTX.

\section{PATIENTS AND METHODS}

\section{Subjects}

Adult outpatients with active arthritis in whom MTX treatment was indicated according to their treating rheumatologist were asked to participate. Concomitant use of other DMARDs, non-steroidal anti-inflammatory drugs (NSAIDs) or corticosteroids was not allowed to be changed from 1 month before the start of treatment until the end of the study. Exclusion criteria were pregnancy, breast feeding, asthma, alcohol abuse ( $>20$ units/week), raised liver enzymes (alanine aminotransferase (ALT) $>3$ times the upper limit), renal insufficiency (estimated clearance $<50 \mathrm{ml} / \mathrm{min})$, thrombocytopenia $\left(<120 \times 10^{9} / 1\right)$, or leucocytopenia $\left(<3.5 \times 10^{9} / 1\right)$. Patients were not allowed to enter the study if they had been treated previously with MTX, or if they were treated currently with sulfasalazine, dipyridamole, folic acid or folinic acid. Folic acid supplementation was not given in the 12 week treatment period to avoid any possible interference with our measurements.

Abbreviations: AICAR, 5-aminoimidazole-4-carboxamide ribonucleotide; ALT, alanine aminotransferase; AMP, adenosine monophosphate; CRP, $C$ reactive protein; DMARD, disease modifying antirheumatic drug; ESR, erythrocyte sedimentation rate; $F B F$, forearm blood flow; HPLC, high performance liquid chromatography; MTX, methotrexate; NSAID, non-steroidal anti-inflammatory drug 


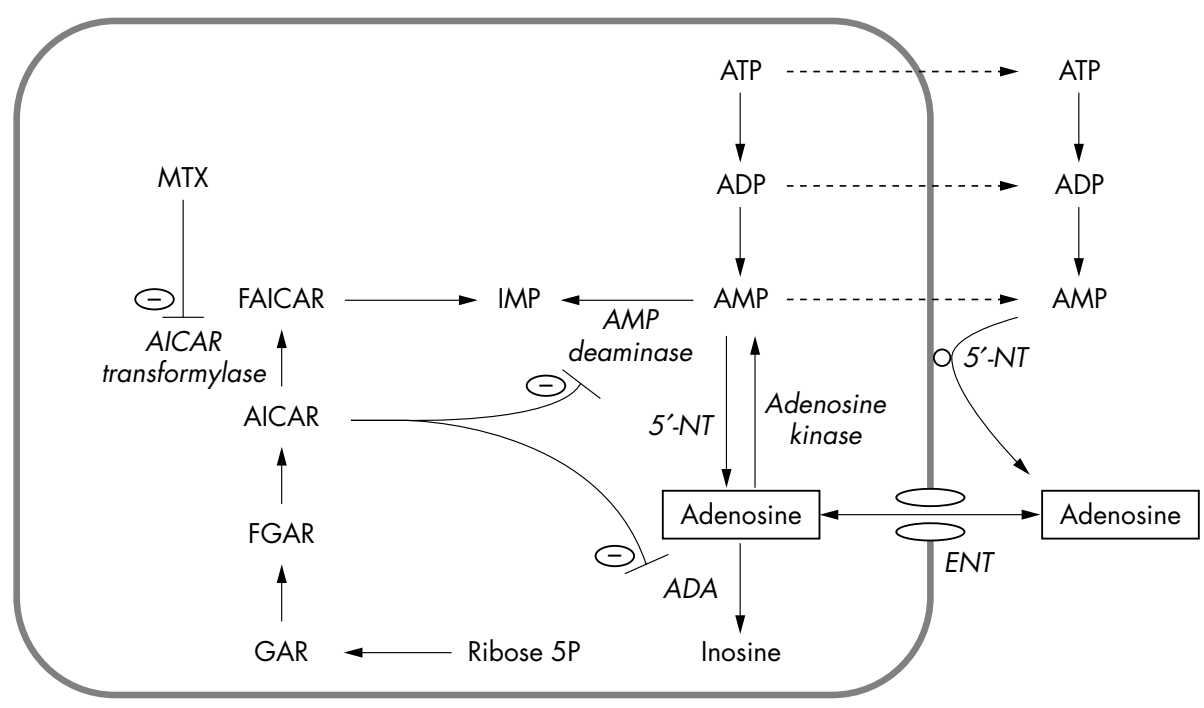

Figure 1 Simplified representation of the effect of methotrexate on adenosine metabolism. Polyglutamate methotrexate inhibits AICAR transformylase, resulting in the intracellular accumulation of AICAR, which inhibits adenosine deaminase and AMP deaminase. Consequently, irreversible degradation of adenosine to inosine is inhibited as well as the conversion of AMP in IMP. Subsequently, AMP is extracellularly converted to adenosine by the ecto-5'nucleotidase. AICAR, 5aminoimidazole-4-carboxamide ribonucleotide; ENT, equilibrative nucleoside transporter; FAICAR, 10formyl AICAR; FGAR, 10-formyl GAR; GAR, glycinamide ribonucleotide; IMP, inosine monophosphate; 5'-NT, 5' nucleotidase.

The study protocol was approved by the Institutional Review Board of the Radboud University Nijmegen Medical Centre and the investigation conforms with the principles outlined in the Declaration of Helsinki. Ten patients agreed to participate and signed written informed consent before participation. Seven patients were diagnosed with rheumatoid arthritis, two patients with psoriatic arthritis, and one patient with an unspecified oligoarthritis. Table 1 shows other baseline characteristics.

\section{Experimental protocol}

All patients started oral treatment with MTX at a dose of $15 \mathrm{mg} /$ week during the study period. Vasodilator effects of adenosine and dipyridamole were assessed before and 12 weeks after the start of treatment, 2 hours after the intake of the weekly MTX dose. All experiments were performed in the morning in a temperature controlled laboratory $\left(23^{\circ} \mathrm{C}\right)$. Participants were asked to abstain from products containing caffeine for at least 24 hours before each experiment because caffeine is an effective adenosine receptor antagonist. ${ }^{17}$ NSAIDs were discontinued for at least 24 hours before each experiment to avoid any influence of cyclo-oxygenase inhibition on vascular function.

On these visits the disease activity score ${ }^{18}$ was obtained by a rheumatologist (PB), and blood was drawn for determination of ALT, alkaline phosphatase, creatinine, total blood count, $\mathrm{C}$ reactive protein (CRP), erythrocyte sedimentation rate (ESR), total plasma homocysteine, and the activity of the adenosine deaminase enzyme in erythrocytes and lymphocytes.

After local anaesthesia (xylocaine $2 \%$ ) the brachial artery of the non-dominant arm was cannulated with a 20-gauge catheter (Angiocath, Deseret Medical, UT, USA) for intraarterial drug administration (automatic syringe infusion

\begin{tabular}{|ll|}
\hline Table 1 & Baseline characteristics of the patients \\
\hline Variable & Mean (SD) \\
\hline Sex (M/F) & $5 / 5$ \\
Age (years) & $53.2(12.0)$ \\
Disease activity score & $4.0(1.1)$ \\
Body mass index $\left(\mathrm{kg} / \mathrm{m}^{2}\right)$ & $24.7(5.4)$ \\
Creatinine $(\mu \mathrm{mol} / \mathrm{l})$ & $88.0(56.4)$ \\
Cholesterol $(\mathrm{mmol} / \mathrm{l})$ & $5.4(0.6)$ \\
Plasma glucose $(\mathrm{mmol} / \mathrm{l})$ & $5.3(0.5)$ \\
\hline
\end{tabular}

Table 2 Laboratory values and haemodynamic measures

\begin{tabular}{lll}
\hline Variable & $\begin{array}{l}\text { Before } \\
\text { methotrexate }\end{array}$ & During methotrexate \\
\hline ALT (U/I) & $20(11)$ & $45(24)^{*}$ \\
Alkaline phosphatase(U/I) & $77(17)$ & $75(23)$ \\
Creatinine $(\mu \mathrm{mol} / \mathrm{I})$ & $88(56)$ & $83(46)$ \\
$\mathrm{CRP}(\mathrm{mg} / \mathrm{l})$ & $24(48)$ & $10(15)$ \\
$\mathrm{ESR}(\mathrm{mm} / \mathrm{lst} \mathrm{h})$ & $15(18)$ & $16(22)$ \\
Haemoglobin $(\mathrm{mmol} / \mathrm{I})$ & $8.1(0.8)$ & $7.7(1.1)$ \\
Leucocytes $\left(\times 10^{9} / \mathrm{I}\right)$ & $7.8(2.8)$ & $7.1(2.4)$ \\
Thrombocytes $\left(\times 10^{9} / \mathrm{I}\right)$ & $253(92)$ & $278(88)$ \\
$\mathrm{SBP}(\mathrm{mm} \mathrm{Hg})$ & $142(20)$ & $139(18)$ \\
DBP $(\mathrm{mm} \mathrm{Hg})$ & $70(7)$ & $70(9)$ \\
Heart rate $(\mathrm{bpm})$ & $65(12)$ & $66(13$ \\
Homocysteine $(\mu \mathrm{mol} / \mathrm{I})$ & $10.6(4.1)$ & $14.9(4.9)^{*}$ \\
\hline Results are shown as mean $(\mathrm{SD})$. & \\
${ }^{*} \mathrm{p}<0.01$ for the effect of methotrexate. & \\
SBP, systolic blood pressure; DBP, diastolic blood pressure.
\end{tabular}

pump, type STC-521, Terumo Corporation, Tokyo, Japan) and blood pressure recording (Hewlett Packard GmbH, Böblingen, Germany). Forearm blood flow (FBF) was registered simultaneously on both arms by venous occlusion plethysmography using mercury-in-silastic strain gauges (Hokanson EC4, Hokanson, Inc, Washington, USA), as previously described. ${ }^{19}$ Each drug dose was infused for 5 minutes and FBF was recorded three times a minute during the last 2 minutes of each infusion. Before each drug infusion, a wrist cuff was inflated to $200 \mathrm{~mm} \mathrm{Hg}$ to exclude hand circulation from the measurements.

Baseline FBF was assessed during infusion of saline into the brachial artery. Subsequently, adenosine was infused in a dose of 0.5 and $1.5 \mu \mathrm{g} / \mathrm{min} / \mathrm{dl}$ of forearm tissue. After 30 minutes of washout, baseline FBF was measured again during infusion of saline and, finally, dipyridamole was infused in a dose of 30 and $100 \mu \mathrm{g} / \mathrm{min} / \mathrm{dl}$.

\section{Analytical methods}

Total plasma homocysteine was determined using reversed phase high performance liquid chromatography (HPLC), as previously described. ${ }^{20}$ For the determination of adenosine deaminase activity, erythrocytes were isolated from freshly drawn blood by centrifugation, washed two times in saline, and resuspended in MOPS buffer ( $10 \mathrm{mM}$ MOPS, $0.9 \% \mathrm{NaCl}$, $\mathrm{pH} 7.4)$ to obtain a $20 \%(\mathrm{vol} / \mathrm{vol})$ solution. Subsequently, the 


\begin{tabular}{|c|c|c|}
\hline Variable & $\begin{array}{l}\text { Before } \\
\text { methotrexate }\end{array}$ & After methotrexate \\
\hline \multicolumn{3}{|c|}{ Lymphocytes } \\
\hline$V_{\text {max }}$ & $20.7(5.6)$ & $16.2(6.0)^{*}$ \\
\hline $\mathrm{K}_{\mathrm{m}}$ & 40.7 (2.9) & $38.3(3.6)$ \\
\hline \multicolumn{3}{|c|}{ Erythrocytes } \\
\hline$V_{\max }^{\prime}$ & $100.9(31.7)$ & 111.3 (42.3) \\
\hline $\mathrm{K}_{\mathrm{m}}$ & $43.9(6.9)$ & $42.6(5.5)$ \\
\hline \multicolumn{3}{|c|}{$\begin{array}{l}\text { Results are shown as mean (SD). } \\
{ }^{*} p<0.05 \text { for the effect of methotrexate. } p>0.1 \text { for other } \\
\text { variables. } \\
V_{\text {max }} \text { values expressed as } \mathrm{nmol} / \mathrm{min} / \mathrm{mg} \text { protein; } \mathrm{K}_{\mathrm{m}} \text { values } \\
\text { expressed as } \mu \mathrm{mol} / \mathrm{l} \text {. }\end{array}$} \\
\hline
\end{tabular}

erythrocytes were lysed by adding six volumes of cold distilled water for 5 minutes. After centrifugation for 10 minutes at $4^{\circ} \mathrm{C}$ the supernatant was stored at $-70^{\circ} \mathrm{C}$ until analysis. Lymphocytes were isolated by Ficoll-Paque centrifugation and were lysed with M-PER mammalian protein extraction reagent in the presence of Halt protease inhibitor cocktail and EDTA solution. After incubation for 10 minutes $\left(22^{\circ} \mathrm{C}\right)$, and centrifugation for 15 minutes, the supernatant was stored at $-70^{\circ} \mathrm{C}$ until analysis.

For determination of adenosine deaminase activity, adenosine was added to lysate in a final concentration of 0,25 , 50, 100, 200, and $300 \mu \mathrm{mol} / \mathrm{l}$ at $37^{\circ} \mathrm{C}$. Each $200 \mu \mathrm{l}$ of incubation mixture contained $25 \mu \mathrm{l}$ cellular lysate and $50 \mathrm{mM}$ Tris- $\mathrm{HCl}$ ( $\mathrm{pH} 7.4$ ). After 15 minutes the reaction was stopped by the addition of $50 \mu \mathrm{l} 1.5 \mathrm{M} \mathrm{HClO}_{4}$ followed by centrifugation (3 minutes). Subsequently, $125 \mu \mathrm{l}$ of the supernatant was mixed with $125 \mu$ trioctylamine in chloroform, and after centrifugation (3 minutes) $50 \mu \mathrm{l}$ of the neutralised upper layer was used for HPLC analysis of inosine and hypoxanthine with ultraviolet detection.

\section{Drugs and solutions}

Solutions of adenosine (Adenocor, Sanofi-Synthelabo, Maassluis, The Netherlands) and dipyridamole (Persantin, Boehringer Ingelheim, Espana SA, Spain) were freshly prepared before each experiment with saline as solvent.

\section{Data analysis}

All data are shown as mean (SD) unless stated otherwise. For each patient, $V_{\max }$ and $\mathrm{K}_{\mathrm{m}}$ values of adenosine deaminase were calculated according to Michaelis-Menten kinetics (GraphPad Prism 4 for Windows). Activity was related to the total protein content in lymphocytes and to the protein content of the membranous fraction in erythrocytes, as determined by the Lowry assay. The effect of MTX treatment on laboratory values and disease activity scores was calculated using a Wilcoxon signed ranks test as not all variables showed a Gaussian distribution.

FBF was measured in both arms simultaneously and the ratio of the FBF in the experimental arm to the control arm (FBF ratio) was calculated to adjust for random changes unrelated to the local stimulus. ${ }^{21}$ The effect of MTX treatment on the vasodilator response to adenosine and dipyridamole was calculated using analysis of variance for repeated measures (SPSS for windows, release 12.0.1).

\section{RESULTS}

One patient was excluded from analysis because MTX treatment had to be discontinued as a result of a rise in ALT activity during the study. The disease activity score was not significantly decreased by MTX (from 4.0 (1.1) to 3.2 (2.0), $\mathrm{n}=9, \mathrm{p}>0.1$ ). Plasma concentrations of CRP and haemoglobin tended to decrease during MTX treatment (table $2, \mathrm{p}=0.1$ ). ALT activity and total plasma homocysteine concentration were significantly increased by MTX treatment (table 2). Other biochemical or haemodynamic measures did not change significantly.

In lymphocytes, but not in erythrocytes, the $\mathrm{V}_{\max }$ value of the enzyme adenosine deaminase was significantly decreased by MTX treatment, whereas $\mathrm{K}_{\mathrm{m}}$ values were not significantly affected (table 3).

Baseline FBF in the experimental arm was similar on both occasions $(2.9(0.9) \mathrm{ml} / \mathrm{min} / \mathrm{dl}$ before and $2.9(0.8) \mathrm{ml} / \mathrm{min} / \mathrm{dl}$ during MTX treatment, $\mathrm{p}>0.1$ ). Also on both occasions, FBF completely returned towards baseline levels after the 30 minute period between the adenosine and dipyridamole infusions, and MTX treatment did not significantly affect FBF in the control arm (data not shown). MTX treatment resulted in a significant enhancement of both adenosineinduced vasodilatation and dipyridamole-induced vasodilatation ( $\mathrm{p}<0.05$; fig 2$)$.

\section{DISCUSSION}

In this study we demonstrated in humans in vivo that MTX treatment inhibits adenosine deaminase. Also, adenosineinduced forearm vasodilatation was significantly potentiated by MTX. This might be due to the decreased intracellular deamination of adenosine, because it was previously shown that adenosine deamination rather than transport of adenosine over the cellular membrane is rate limiting for the overall catabolism of adenosine. ${ }^{22}$ We also showed that dipyridamole-induced vasodilatation is potentiated by MTX treatment. This observation indicates that, besides inhibition of

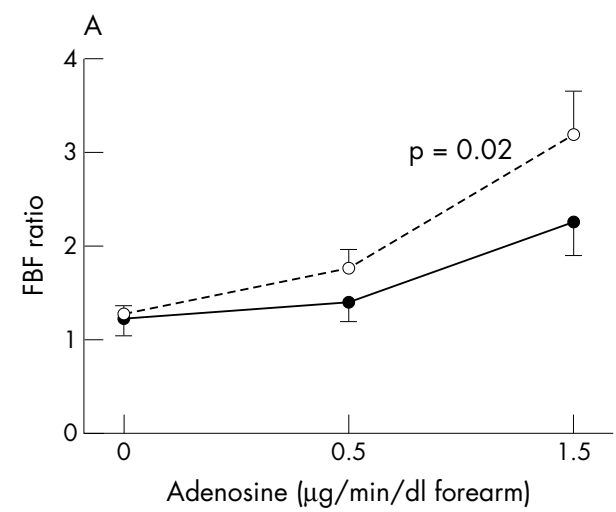

Figure 2 Forearm vasodilatation (mean (SE)) induced by the infusion of adenosine (A) and dipyridamole (B) into the brachial artery before the start of MTX treatment (filled circles) and after 12 weeks of treatment (open circles). $p$ Values denote the results of analysis of variance for repeated measures. 
intracellular degradation, also extracellular formation of endogenous adenosine is increased, which is compatible with previous in vitro findings. ${ }^{23}$ In conclusion, we demonstrated for the first time in humans in vivo that treatment with MTX potentiates adenosine $\mathrm{A}_{2 \mathrm{~A}}$ receptor mediated effects.

The effect of MTX on the metabolism of adenosine was first described by Cronstein et al ex vivo and in animal experiments. ${ }^{24}$ They showed that in isolated human fibroblasts and endothelial cells, pretreatment with MTX increases extracellular adenosine. Recently, it was demonstrated that in a rat model of adjuvant arthritis, adenosine receptor antagonists completely abolish the anti-inflammatory effects of MTX. ${ }^{25}$ Moreover, in adenosine $\mathrm{A}_{2 \mathrm{~A}}$ and $\mathrm{A}_{3}$ receptor knockout mice, MTX treatment no longer induces any antiinflammatory effects. ${ }^{26}$

Human in vivo data on the potential role of adenosine in the mechanism of action of MTX are scarce, controversial, and indirect. Two recent reports suggest that a high intake of caffeinated products diminishes the antirheumatic effect of MTX. $^{89}$ As caffeine is an effective adenosine receptor antagonist already at concentrations reached after regular coffee consumption, ${ }^{27}$ this is consistent with a role for adenosine receptor stimulation in the mechanism of action of MTX. Interventional studies which determined adenosine concentration before and after administration of MTX provided controversial results, and most studies showed negative results. ${ }^{10-14}$ An important reason for these inconsistent and mostly negative results is the duration of MTX treatment. It is necessary to give MTX for several days to weeks to permit polyglutamation and intracellular accumulation of 5-aminoimidazole-4-carboxamide ribonucleotide (AICAR), which is required for enhanced adenosine formation. ${ }^{26}$ In contrast, in most previous studies, adenosine concentrations were determined after at most 1 day ${ }^{1-13}$ or a few days. ${ }^{10}$ Also, reliable measurement of adenosine is highly cumbersome as its half life is less than 1 second and the endothelium constitutes an active metabolic barrier for adenosine, resulting in a functional compartmentalisation of adenosine..$^{15}$ In the present study, we gave MTX for 12 weeks and bypassed the methodological difficulties of adenosine determination by using adenosine- and dipyridamole-induced vasodilatation as a reflection of adenosine degradation and formation, respectively.

The mechanism by which MTX affects the kinetics and dynamics of adenosine has partially been elucidated by previous animal studies. Most probably, MTX interferes with the de novo purine synthesis pathway in cells. ${ }^{39}$ Polyglutamates of MTX, the long lived intracellular metabolites of MTX, are potent competitive inhibitors of the enzyme AICAR transformylase, resulting in the intracellular accumulation of $\operatorname{AICAR}^{29}$ (fig 1). In turn, it has been shown in vitro that AICARiboside inhibits catalytic activity of adenosine deaminase, ${ }^{29}{ }^{30}$ and AICARibotide inhibits AMP deaminase. ${ }^{29}$ Morabito et al showed that the anti-inflammatory effects of MTX could be abolished by inhibition of ecto- $5^{\prime}$-nucleotidase, ${ }^{23}$ emphasising the importance of extracellular conversion of AMP to adenosine. It was suggested that inhibition of AMP deaminase promotes release of adenine nucleotides, by an as yet unidentified mechanism, which are converted by extracellular 5'-nucleotidase to adenosine (fig 1).

Our study provides additional mechanistic insight, which links up nicely with the abovementioned previous findings. It was previously shown in humans that MTX treatment decreases the activity of adenosine deaminase. However, the effects of MTX on the $V_{\max }$ and $\mathrm{K}_{\mathrm{m}}$ values of this enzyme were not assessed. ${ }^{31}$ The present study showed that MTX decreases the $\mathrm{V}_{\max }$ but not the $\mathrm{K}_{\mathrm{m}}$ of adenosine deaminase in lymphocytes. Unfortunately, from these results it cannot be concluded whether this observed change is due to direct non-competitive enzyme inhibition or decreased enzyme levels, or whether this reflects changes in lymphocyte subpopulations, which could differ in their adenosine deaminase activity. ${ }^{32}$

To provide further evidence that MTX modulates adenosine metabolism by interfering with de novo purine synthesis, we also determined the activity of adenosine deaminase in erythrocytes, a cell type that lacks the capacity for de novo purine synthesis. ${ }^{33}$ Indeed, in these cells we observed no change of activity of adenosine deaminase during MTX treatment. Unfortunately, we were not able to assess enzymatic activity of other enzymes involved in purine metabolism, such as AMP deaminase and ecto-5' -nucleotidase. It has to be realised that erythrocytes are responsible for the bulk of breakdown of circulating adenosine and that therefore adenosine deamination in lymphocytes probably only has a minor role in the observed increased adenosineinduced vasodilatation in our study. However, endothelial cells and vascular smooth muscle cells contribute significantly to adenosine metabolism. ${ }^{34}$ We postulate that in these cells, adenosine deaminase activity is also reduced, resulting in an increased adenosine concentration which can stimulate adenosine receptors on these cells. In contrast with the breakdown of circulating adenosine, lymphocytes may have an important role in the regulation of adenosine concentration in areas of inflammation. Therefore, the decreased adenosine deaminase activity in lymphocytes could contribute to the anti-inflammatory effect of MTX.

Additional mechanistic information was obtained from the in vivo part of this study. As dipyridamole prevents cellular uptake of endogenous adenosine, it increases the extracellular concentration of adenosine at a rate which is proportional to extracellular formation of adenosine. We have demonstrated previously that dipyridamole-induced vasodilatation in humans is indeed due to inhibition of cellular adenosine uptake: dipyridamole potentiates the vasodilator response to adenosine, ${ }^{35}$ it increases the adenosine concentration in the forearm venous effluent during administration of adenosine into the brachial artery, ${ }^{36}$ and dipyridamoleinduced vasodilatation $(100 \mu \mathrm{g} / \mathrm{min} / \mathrm{dl})$ is inhibited by the adenosine receptor antagonist theophylline. ${ }^{37}$ The present study shows that dipyridamole-induced vasodilatation is significantly enhanced during MTX treatment. This finding translates the previous in vitro finding of increased extracellular dephosphorylation of AMP during treatment with $\mathrm{MTX}^{23}$ to the human in vivo situation.

The present study showed that MTX treatment potentiates the vasodilator effect of adenosine. It has to be realised that adenosine receptor stimulation not only inhibits inflammation and induces vasodilatation but also initiates various cardiovascular effects, such as negative inotropic and chronotropic cardiac effects, presynaptic inhibition of sympathetic neurotransmitter release, inhibition of vascular smooth muscle cell proliferation, and inhibition of thrombocyte aggregation. ${ }^{7}$ Also, adenosine receptor stimulation renders the myocardium more resistant to ischaemia and reperfusion injury. ${ }^{38}$ Taken together, these effects have the potential to protect the heart during ischaemia and prevent or slow down the process of atherosclerosis. Patients with rheumatoid arthritis have a higher incidence of cardiovascular disease than the general population. ${ }^{39} 40$ Interestingly, a recent study suggested that the beneficial effect of MTX on cardiovascular mortality is better than that of other antirheumatic drugs, ${ }^{41}$ although another study did not find this benefit. ${ }^{42}$ When considering the abovementioned cardiovascular effects of adenosine, one can easily appreciate that increased adenosine receptor stimulation could be responsible for this beneficial cardiovascular effect of MTX. Indeed, it was shown previously 
in canine hearts that MTX limits myocardial infarct size via adenosine dependent mechanisms. ${ }^{43}$

Finally, the potential limitations of our study need to be discussed. It has to be realised that due to the use of a clinical study population in need of immediate treatment the design of the present study was open label and non-randomised. In healthy volunteers a more sophisticated design would have been possible, but in our opinion it is unethical to give MTX to healthy volunteers for a long time. We ensured that the use of other (anti-inflammatory) drugs was kept constant during the study period, in order to prevent confounding by other drugs. Finally, plasma homocysteine concentration needs to be considered as a determinant of adenosine-induced vasodilatation. MTX treatment increases plasma homocysteine concentration by interfering with folate dependent remethylation of homocysteine. ${ }^{44}$ Any increase in plasma homocysteine, in turn, could stimulate synthesis of $S$ adenosylhomocysteine at the expense of free adenosine, as we previously described. ${ }^{45}{ }^{46}$ Also, hyperhomocysteinaemia induces endothelial dysfunction. ${ }^{47}$ Fortunately, these potential effects of homocysteine on vascular reactivity are opposite to our present findings, and therefore our conclusion would have been even more convincing if we had been able to correct for the rise in homocysteine.

Our study adds important human in vivo data to the growing body of evidence that adenosine is an important mediator of the therapeutic efficacy of MTX in patients with rheumatoid arthritis. These insights provide potential alternative targets for pharmacological intervention in these patients, such as adenosine uptake inhibition. Dipyridamole, either alone or added to MTX, also increases extracellular endogenous adenosine and thus would also be expected to suppress inflammation in this patient group. To our knowledge, this potential anti-inflammatory effect of dipyridamole has never been systematically studied in a clinical population.

\section{ACKNOWLEDGEMENTS}

Niels P Riksen is a recipient of a fellowship of the Netherlands Organisation for Scientific Research (ZonMw). Gerard A Rongen is a fellow of the Royal Netherlands Academy of Arts and Sciences (KNAW). We would like to thank Dr Henk Blom and Diny van Oppenraaij for the determination of homocysteine.

\section{Authors' affiliations \\ N P Riksen, P H H van den Broek, P Smits, G A Rongen, Department of Pharmacology-Toxicology, Radboud University Nijmegen Medical Centre, PO Box 9101, 6500 HB, Yhe Netherlands}

N P Riksen, P Smits, G A Rongen, Department of Internal Medicine, Radboud University Nijmegen Medical Centre, PO Box 9101, 6500 HB, The Netherlands

P Barrera, P L C M van Riel, Department of Rheumatology, Radboud University Nijmegen Medical Centre, PO Box 9101, 6500 HB, The Netherlands

Conflict of interest: None.

\section{REFERENCES}

1 ACR. American College of Rheumatology Subcommittee on Rheumatoid Arthritis Guidelines. Guidelines for the management of rheumatoid arthritis: 2002 update, Arthritis Rheum 2002;46:328-46.

2 Cronstein BN. Low-dose methotrexate: a mainstay in the treatment of rheumatoid arthritis. Pharmacol Rev 2005;57:163-72.

3 Cutolo M, Sulli A, Pizzorni C, Seriolo B, Straub RH. Anti-inflammatory mechanisms of methotrexate in rheumatoid arthritis. Ann Rheum Dis $2001 ; 60: 729-35$

4 Fredholm BB, ljzerman AP, Jacobson KA, Klotz KN, Linden J. International Union of Pharmacology. XXV. Nomenclature and classification of adenosine receptors. Pharmacol Rev 2001;53:527-52.

5 Deussen A, Stappert M, Schafer S, Kelm M. Quantification of extracellular and intracellular adenosine production: understanding the transmembranous concentration gradient. Circulation 1999;99:2041-7.
6 Hasko G, Cronstein BN. Adenosine: an endogenous regulator of innate immunity. Trends Immunol 2004;25:33-9.

7 Rongen GA, Floras JS, Lenders JW, Thien T, Smits P. Cardiovascular pharmacology of purines. Clin Sci (Lond) 1997:92:13-24.

8 Silke C, Murphy MS, Buckley T, Busteed S, Molloy MG, Phelan M. The effects of caffeine ingestion on the efficacy of methotrexate [abstract]. Rheumatology (Oxford) 2001:40:34

9 Nesher G, Mates M, Zevin S. Effect of caffeine consumption on efficacy of methotrexate in rheumatoid arthritis. Arthritis Rheum 2003;48:571-2.

10 Smolenska Z, Kaznowska Z, Zarowny D, Simmonds HA, Smolenski RT. Effect of methotrexate on blood purine and pyrimidine levels in patients with rheumatoid arthritis. Rheumatology 1999;38:997-1002.

11 Laghi-Pasini F, Capecchi PL, Di Perri T. Adenosine plasma levels after low dose methotrexate administration. J Rheumatol 1997;24:2492-3.

12 Egan LJ, Sandborn WJ, Mays DC, Tremaine WJ, Lipsky JJ. Plasma and rectal adenosine in inflammatory bowel disease: effect of methotrexate. Inflamm Bowel Dis 1999;5:167-73.

13 Baggott JE, Morgan SL, Sams WM, Linden J. Urinary adenosine and aminoimidazolecarboxamide excretion in methotrexate-treated patients with psoriasis. Arch Dermatol 1999;135:813-7.

14 Dolezalova P, Krij† J, Chladek J, Nemcova D, Hoza J. Adenosine and methotrexate polyglutamate concentrations in patients with juvenile arthritis. Rheumatology (Oxford) 2005;44:74-9.

15 Moser GH, Schrader J, Deussen A. Turnover of adenosine in plasma of human and dog blood. Am J Physiol 1989;256:C799-806.

16 Riksen NP, Oyen WJG, Ramakers BP, van den Broek PHH, Engbersen R, Boerman OC, et al. Oral therapy with dipyridamole limits ischemiareperfusion injury in humans. Clin Pharmacol Ther 2005;78:52-9.

17 Smits $\mathbf{P}$, Lenders JW, Thien T. Caffeine and theophylline attenuate adenosineinduced vasodilation in humans. Clin Pharmacol Ther 1990;48:410-18.

18 Prevoo ML, van ' $t$ Hof MA, Kuper HH, van Leeuwen MA, van de Putte LB, van Riel PL. Modified disease activity scores that include twenty-eight-joint counts. Development and validation in a prospective longitudinal study of patients with rheumatoid arthritis. Arthritis Rheum 1995:38:44-8.

19 Rongen GA, Ginneken E, Thien T, Lutterman JA, Smits P. Preserved vasodilator response to adenosine in insulin-dependent diabetes mellitus. Eur J Clin Invest 1996;26:192-8.

20 te Poele-Pothoff MT, van den Berg M, Franken DG, Boers GH, Jakobs C, de Kroon IF, et al. Three different methods for the determination of total homocysteine in plasma. Ann Clin Biochem 1995;32:218-20.

21 Petrie JR, Ueda S, Morris AD, Murray LS, Elliott HL, Connell JM. How reproducible is bilateral forearm plethysmography? $\mathrm{Br} J$ Clin Pharmacol 1998;45:131-9

22 Snoeck E, Ver DK, Jacqmin P, Van Belle H, Dupont AG, Van Peer A, et al. Physiological red blood cell kinetic model to explain the apparent discrepancy between adenosine breakdown inhibition and nucleoside transporter occupancy of draflazine. J Pharmacol Exp Ther 1998;286:142-9.

23 Morabito L, Montesinos MC, Schreibman DM, Balter L, Thompson LF, Resta R, et al. Methotrexate and sulfasalazine promote adenosine release by a mechanism that requires ecto-5'-nucleotidase-mediated conversion of adenine nucleotides. J Clin Invest 1998;101:295-300.

24 Cronstein BN, Eberle MA, Gruber HE, Levin RI. Methotrexate inhibits neutrophil function by stimulating adenosine release from connective tissue cells. Proc Natl Acad Sci USA 1991;88:2441-5.

25 Montesinos MC, Yap JS, Desai A, Posadas I, McCrary CT, Cronstein BN. Reversal of the antiinflammatory effects of methotrexate by the nonselective adenosine receptor antagonists theophylline and caffeine: evidence that the antiinflammatory effects of methotrexate are mediated via multiple adenosine receptors in rat adjuvant arthritis. Arthritis Rheum 2000;43:656-63.

26 Montesinos MC, Desai A, Delano D, Chen JF, Fink JS, Jacobson MA, et al. Adenosine A2A or A3 receptors are required for inhibition of inflammation by methotrexate and its analog MX-68. Arthritis Rheum 2003;48:240-7.

27 Fredholm BB, Battig K, Holmen J, Nehlig A, Zvartau EE. Actions of caffeine in the brain with special reference to factors that contribute to its widespread use. Pharmacol Rev 1999;51:83-133.

28 Nees S, Herzog V, Becker BF, Bock M, Des RC, Gerlach E. The coronary endothelium: a highly active metabolic barrier for adenosine. Basic Res Cardiol 1985:80:515-29.

29 Baggott JE, Vaughn WH, Hudson BB. Inhibition of 5-aminoimidazole-4carboxamide ribotide transformylase, adenosine deaminase and 5'adenylate deaminase by polyglutamates of methotrexate and oxidized folates and by 5-aminoimidazole-4-carboxamide riboside and ribotide. Biochem J 1986:236:193-200.

30 Allegra CJ, Drake JC, Jolivet J, Chabner BA. Inhibition of phosphoribosylaminoimidazolecarboxamide transformylase by methotrexate and dihydrofolic acid polyglutamates. Proc Natl Acad Sci USA 1985:82:4881-5

31 van Ede $A E$, Laan RF, De Abreu RA, Stegeman $A B$, van de Putte $L B$. Purine enzymes in patients with rheumatoid arthritis treated with methotrexate. Ann Rheum Dis 2002;61:1060-4.

32 Massaia M, Ma DD, Sylwestrowicz TA, Tidman N, Price G, Janossy G, et al. Enzymes of purine metabolism in human peripheral lymphocyte subpopulations. Clin Exp Immunol 1982;50:148-54.

33 Fontenelle L, Henderson JF. An enzymatic basis for the inability of erythrocytes to synthesize purine ribonucleotides de novo. Biochim Biophys Acta 1969;177:175-6.

34 Mattig S, Deussen A. Significance of adenosine metabolism of coronary smooth muscle cells. Am J Physiol Heart Circ Physiol 2001;280:H1 17-24.

35 van Ginneken EE, Rongen GA, Russel FG, Smits P. Diadenosine pentaphosphate vasodilates the forearm vascular bed: inhibition by 
theophylline and augmentation by dipyridamole. Clin Pharmacol Ther 2002;71:448-56

36 Riksen NP, van Ginneken EE, Van den Broek PH, Smits P, Rongen GA. In vivo evidence against a role for adenosine in the exercise pressor reflex in humans. $J$ Appl Physiol 2005;99:522-7.

37 Bijlstra P, van Ginneken EE, Huls M, Van Dijk R, Smits P, Rongen GA. Glyburide inhibits dipyridamole-induced forearm vasodilation but not adenosine-induced forearm vasodilation. Clin Pharmacol Ther 2004;75:147-56

38 Headrick JP, Hack B, Ashton KJ. Acute adenosinergic cardioprotection in ischemic-reperfused hearts. Am J Physiol Heart Circ Physiol 2003;285: H1797-818

39 Turesson C, Jarenros A, Jacobsson L. Increased incidence of cardiovascular disease in patients with rheumatoid arthritis: results from a community based study. Ann Rheum Dis 2004;63:952-5.

40 Solomon DH, Karlson EW, Rimm EB, Cannuscio CC, Mandl LA, Manson JE, et al. Cardiovascular morbidity and mortality in women diagnosed with rheumatoid arthritis. Circulation 2003:107:1303-7.

41 Choi HK, Hernan MA, Seeger JD, Robins JM, Wolfe F. Methotrexate and mortality in patients with rheumatoid arthritis: a prospective study. Lancet 2002;359:1173-7.
42 Landewe RB, van den Borne BE, Breedveld FC, Dijkmans BA. Methotrexate effects in patients with rheumatoid arthritis with cardiovascular comorbidity. Lancet 2000;355:1616-17.

43 Asanuma H, Sanada S, Ogai A, Minamino T, Takashima S, Asakura M, et al. Methotrexate and MX-68, a new derivative of methotrexate, limit infarct size via adenosine-dependent mechanisms in canine hearts. J Cardiovasc Pharmacol 2004;43:574-9.

44 van Ede AE, Laan RF, Blom HJ, Boers GH, Haagsma CJ, Thomas $C M$, et al. Homocysteine and folate status in methotrexate-treated patients with rheumatoid arthritis. Rheumatology (Oxford) 2002;41:658-65.

45 Riksen NP, Rongen GA, Blom HJ, Russel FGM, Boers GHJ, Smits P. Potential role for adenosine in the pathogenesis of the vascular complications of hyperhomocysteinemia. Cardiovasc Res 2003;59:271-6.

46 Riksen NP, Rongen GA, Boers GHJ, Blom HJ, van den Broek PHH, Smits P. Enhanced cellular adenosine uptake limits adenosine receptor stimulation in patients with hyperhomocysteinemia. Arterioscler Thromb Vasc Biol 2005:25:109-14.

47 Bellamy MF, McDowell IF, Ramsey MW, Brownlee M, Bones $C$ Newcombe RG, et al. Hyperhomocysteinemia after an oral methionine load acutely impairs endothelial function in healthy adults. Circulation 1998;98:1848-52. 